\title{
Choice of Maize Genotype Affects Wheat Haploid Seed and Success of Embryo Rescue
}

\section{Muhammad llyas Khokhar ${ }^{1, *}$, Abdul Razaq ${ }^{1}$, Junaid Iqbal2 ${ }^{2}$, Muhammad Jamshaid Anwar ${ }^{1}$, Muhammad Zaffar Iqbal', Sajid ur Rehman ${ }^{1}$}

${ }^{1}$ Agricultural Biotechnology Research Institute, Ayub Agricultural Research Institute, Faisalabad, Pakistan 2Department Plant Breeding and Genetics, University of Agriculture (UAF), Faisalabad, Pakistan

\section{ABSTRACT}

In wheat (Triticum aestivum) breeding, the use of double haploids plays a vital role by reducing the length of the breeding cycle. The first step in the production of a wheat double haploid is to create a haploid, which in wheat can be achieved via wheat $\times$ maize cross, and resulting haploid plants are recovered by embryo rescue. In this study, a wheat segregating population $\left(F_{2}\right)$ was emasculated and pollinated with pollen from four maize varieties (Sadaf, Malka-2016, Pearl and MMRI yellow). Maize genotype affected the outcome of haploid seed production (Sadaf $=28.58 \%$; Pearl $=28.33 \%$; Malka-2016 $=26.42 \%$; MMRI yellow $=17.97 \%$ ) and embryo rescue (Malka-2016 $=27.02 \%$; MMRI yellow $=25.82 \%$; Sadaf $=20.17 \%$; Pearl $=16.47 \%$ ). Sadaf produced maximum haploid seed (28.58\%) followed by Pearl (28.33\%) but higher embryo rescued success (27.02\%) was observed in Malka-2016 followed by MMRI $(25.82 \%)$. We recommend the use of Sadaf or Malka-2016 to produce haploid seed and to achieve successful embryo rescue in wheat $\times$ maize crossing for wheat doubled haploid production.

Keywords

2, 4-D, haploid embryo induction, embryo rescue.
*Address of Correspondence

khokharab@yahoo.com,

ilyasabri@yahoo.com

Cite this article: Khokhar MI, Razaq A, Iqbal J, Anwar MJ, Iqbal MZ, Rehman S. Choice of Maize Genotype Affects Wheat Haploid Seed and Success of Embryo Rescue. RADS J. Biol. Res. Appl. Sci. 2019; 10(1): 1-5.

This is an Open Access article distributed under the terms of the Creative Commons Attribution License (http://creativecommons.org/licenses/by/4.0), which permits unrestricted use, distribution, and reproduction in any medium, provided the original work is properly cited.

\section{INTRODUCTION}

Double haploid $(\mathrm{DH})$ development is a powerful technique to accelerate the conventional breeding program. DHs are extensively used for genetic studies i.e. inheritance of quantitative traits, genomics, gene identification, quantitative trait loci (QTL) mapping, whole genome mapping and production of stable transgenic plants' 1 .

Several methods including parthenogenesis, apogamy, anther/microspore culture, ovary culture and wide hybridization have been developed to produce haploid plants ${ }^{2}$. Anther-culture and chromosome elimination techniques were used for, haploid wheat plants. But anther-culture technique is not effective as it is greatly influenced by wheat genotype ${ }^{3}$. Chromosome elimination technique was applied by Campbell et al. in wheat ${ }^{4}$. The mechanism behind chromosome elimination in wheat $x$ maize crossing system is that after pollination maize pollen germinates on stigma and reaches to embryo sac to fertilize wheat egg. After the fertilization a hybrid is produced with 21 wheat chromosomes and 10 maize chromosomes. Centromeres on chromosomes lose their strength to attach with the spindle fiber, maize chromosomes eliminate after 2 to 3 cell division ultimately haploid embryo with 21 wheat chromosomes are formed 5 . Kazi et al., ${ }^{6}$ stated that maize pollen is an effective factor for haploid seed development. Khan et al., ${ }^{5}$ studied the effect of five maize genotypes (Neelum, Sadaf, Sultan, Agaiti-2002 and Agaiti-85) as male parent in wheat $x$ maize crossing and observed significant effects on haploid seeds formation and embryos production. Other 
factors that affect haploid seeds production in wheat $x$ maize technique are growth conditions of the wheat and maize plants, mode of growth regulator application, genotype, time of embryo rescue, and embryo rescue medium 5 .

The present study was conducted to examine the effect of different maize genotypes on haploid seed formation and to assess the success of survival of rescued embryos.

\section{METHODOLOGY}

The research was conducted in Cytogenetic laboratory and experimental area of Agricultural Biotechnology Research Institute (ABRI), Ayub Agricultural Research Institute (AARI) Faisalabad, Pakistan during 2017-18. The experiments were laid out as completely randomized design (CRD), replicated thrice and 20 spikes emasculated for each replication and treatment.

\section{Plant Material}

Wheat segregated material $\left(F_{2}\right)$ of the desirable cross (Ufaq-2002×AARI-11) was sown in an open field during November, 2017. Four maize commercial varieties i.e. Malka-2016, Pearl, MMRI Yellow and Sadaf obtained from Maize and Millet Research Institute, Yousafwala, Pakistan and were sown in a high tunnel (artificial structure made with iron and covered with polythene sheet, length 50 feet and width 10 feet) (Figure 1a) with 8 days interval i.e. $8,16,24,32,40$ and 48 days after $1^{\text {st }}$ date of sowing (31 October, 2017) to ensure maize pollen availability throughout the reproductive stage of wheat crop for pollination from February to March 2018.

\section{Emasculation}

The first set of wheat tillers were selected for emasculation from 19th February 2018 when booting occurred and cut from the base with appropriate length $(92-95 \mathrm{~cm})$. All leaves were removed from the tiller except flag leaf to avoid evapotranspiration and also detached central floret of each spikelet with the help of forceps to easily emasculate the lateral florets. One-third portion of lateral florets also cut from the top to accelerate the emasculation and pollination. Then anthers removed with forceps and emasculated spikelets were covered with butter paper bag to avoid from outcrossing, tagged and mentioned date of emasculation. Twenty spikes per replication were emasculated and crossed with four maize genotypes. Emasculated tillers were kept in the tap water jar and placed in a growth room under controlled temperature, light?.

\section{Pollination}

After 72 hours of emasculation, fresh maize pollens were collected in a petri dishes (Figure 1b) and wheat spikelets were pollinated with the help of camel hair brush within 10-12 minutes (Figure 1c). Pollinated spikes were kept in medium (a) (Table 1) for two days and these tillers were taken out from medium (a) and kept into medium (b) detailed in Table 1 (Figure 1d). Growth media changed every 72 hours for twelve days then haploid seeds were separated from spikes.

Table 1. Three different media composition used for haploid seed production.

\begin{tabular}{|c|c|}
\hline Medium & Composition \\
\hline Medium (a) & $\begin{array}{c}10 \mathrm{mg} / \mathrm{L} 2,4-\mathrm{D}+6 \% \mathrm{H}_{2} \mathrm{SO}_{3}+40 \\
\text { g/L sucrose }\end{array}$ \\
\hline Medium (b) & $6 \% \mathrm{H}_{2} \mathrm{SO}_{3}+40 \mathrm{~g} / \mathrm{L}$ sucrose \\
\hline $1 / 2 \mathrm{MS}$ medium (c) & $\begin{array}{c}2.22 \mathrm{~g} / \mathrm{L} \mathrm{MS}+2.0 \mathrm{~g} / \mathrm{L} \text { Phyta gel + } \\
30 \mathrm{~g} / \mathrm{L} \text { sucrose }\end{array}$ \\
\hline
\end{tabular}

\section{Embryo Rescue}

Developed haploid seeds had whitish in colour, small in size and absent of endosperm as described by Khan et al., ${ }^{5}$, placed in a petri dish (Figure 1f) then seeds were surface sterilized with $1 \%$ clorex (Clorox Chemical Co., Oakland, USA), added two drops of tween-20 and placed for 15 minutes on water bath shaker. Haploid seeds were washed three times with autoclaved distilled water in laminar air flow cabinet (Gelaire, Italy, model HF96). Haploid seed (Figure 1g) was dissected under stereomicroscope (model: TL2, Meiji Techno, Japan), haploid embryo rescued and put into autoclaved half strength $\mathrm{MS}^{8}$ as earlier described by Khan et al., ${ }^{5}$. The whole procedure was performed under a laminar flow cabinet (streamline laboratory product, Singapore). The $\mathrm{pH}$ of the $1 / 2 \mathrm{MS}$ medium was adjusted at 5.8 by adding $1 \mathrm{~N} \mathrm{HCl}$ or $1 \mathrm{~N} \mathrm{NaOH}$ before autoclave. The media were then autoclaved at $15 \mathrm{psi}$ for $20 \mathrm{~min}$ at $120^{\circ} \mathrm{C}$ according to Khokhar et al., ${ }^{9}$. Haploid embryo rescued by examining under stereomicroscope in laminar flow cabinet and put 
into $1 / 2$ MS medium test tubes (length $15 \mathrm{~cm}$ and diameter $2.5 \mathrm{~cm}$ ), covered with polypropylene paper and placed in an incubation room at $22 \mathrm{C}^{0}$ under dark period for two weeks according to Khan et al., ${ }^{5}$.

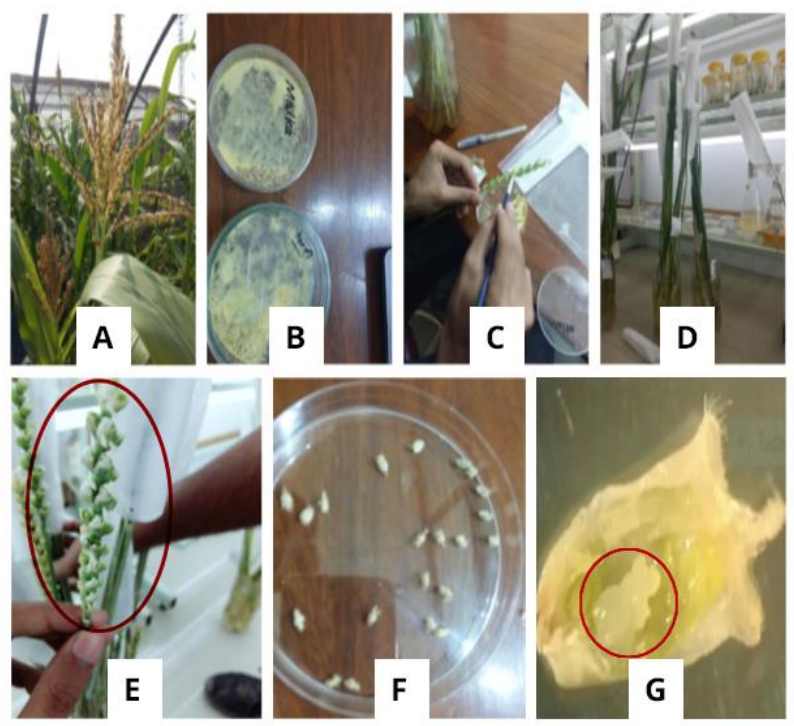

Figure 1. (a) Maize tassel; (b) maize pollen collection; (c) pollination; (d) pollinated spikes; (e) haploid seeds in spikelets; (f) haploid seeds; (g) haploid embryo.

\section{Data Collection}

Number of haploid seeds: Haploid seeds developed were counted and found sum of total haploid seeds from three repeats of each cross.

Number of embryos rescued: Number of embryos rescued were recorded as sum of total embryos rescued of each cross per repeat.

Haploid seeds produced (\%): Haploid seeds production percentage were counted by using this formula.

Haploid Seed Produced $(\%)=\frac{\text { Total haploid seeds }}{\text { Total florets }} \times 100$

Haploid embryo rescued (\%): Haploid embryos rescued percentage were found by using this equation.

Haploid embryo rescued $(\%)=\frac{\text { Total embryo rescued }}{\text { Total haploid seed }} \times 100$

Embryo formed in florets (\%): Embryo formed in florets was counted by using this formula.

Embryo formed in florets $(\%)=\frac{\text { Total embryos rescued }}{\text { Total florets }} \times 100$

\section{Statistical Analysis}

Data were analyzed with statistics 8.1 software program (Table 2). Mean variance of wheat $\times$ maize crosses with a success percentage of haploid embryo rescue was calculated by the least significant difference (LSD) at $a=$ 0.05 (Table 3).

Table 2. Analysis of variance four maize genotypes on haploid embryos rescue success percentage.

\begin{tabular}{cccccc}
\hline SOV & DF & SS & MS & $\begin{array}{c}\mathbf{F} \\
\text { Value }\end{array}$ & $\begin{array}{c}\mathbf{P} \\
\text { Value }\end{array}$ \\
\hline Treatment & 3 & 206.267 & 68.7556 & $5.15^{*}$ & 0.0285 \\
\hline Error & 8 & 106.900 & 13.3625 & & \\
\hline Total & 11 & 313.167 & & & \\
\hline CV & & 16.08 & & \\
\hline
\end{tabular}

Table 3. LSD test for haploid seed production and embryo rescue success $(\%)$ in wheat $\times$ maize crosses.

\begin{tabular}{ccc}
\hline Crosses & $\begin{array}{c}\text { Haploid Seed } \\
\text { Production }\end{array}$ & $\begin{array}{c}\text { Embryo Rescue } \\
\text { Success }(\%)\end{array}$ \\
\hline $\begin{array}{c}\text { Wheat }\left(F_{2}\right) X \\
\text { Sadaf }\end{array}$ & $74.33 \mathrm{~B}$ & $21.20 \mathrm{~B}$ \\
\hline $\begin{array}{c}\text { Wheat }\left(\mathrm{F}_{2}\right) \mathrm{X} \\
\text { Malka-2016 }\end{array}$ & $74.00 \mathrm{~B}$ & $27.13 \mathrm{~A}$ \\
\hline $\begin{array}{c}\text { Wheat }\left(\mathrm{F}_{2}\right) \mathrm{X} \\
\text { Pearl }\end{array}$ & $85.00 \mathrm{~A}$ & $16.67 \mathrm{C}$ \\
\hline $\begin{array}{c}\text { Wheat }\left(\mathrm{F}_{2}\right) \mathrm{X} \\
\text { MMRI yellow }\end{array}$ & $50.33 \mathrm{C}$ & $25.93 \mathrm{~A}$ \\
\hline LSD $(\mathrm{a}=0.05)$ & 2.306 & 2.985 \\
\hline
\end{tabular}

\section{RESULTS AND DISCUSSION}

240 spikes of wheat in the filial generation $\left(F_{2}\right)$ were emasculated and pollinated with four maize varieties. 3360 florets (about 14 florets/ spike) were pollinated which produced 861 haploid seeds (25.34\%) Table 2 and out of these 186 embryos were rescued. It was observed maximum haploid seeds produced 223 from 780 florets (28.58\%) in "Sadaf" followed by 222 from 840 (28.33\%) in pearl, 255 from $900(26.42 \%)$ in "Malka-2016", while minimum 151 out of $840(17.97 \%)$ in "MMRI yellow" were noted as explained in Table 4. Niroula et al., ${ }^{10}$ analyzed different maize genotypes and the results showed that "Arun-2" formed 24 embryos out of 111 pollinated floret followed by "Khumal Yellow" which resulted in 22 embryos from 116 whereas "Rampur Composite" resulted in a minimum number of 5 embryos from 91 pollinated floret. Our study showed better results were obtained 223 
haploid seed out of 780 florets when "Sadaf" used as maize source followed by 255 out of 900 florets from "Pearl" with $28.58 \%$ and $28.33 \%$, respectively. These studies revealed that different maize genotypes helped in better haploid seed development. embryos setting in "Sadaf" (19.13\%) followed by "Neelum" $(13.20 \%)$ while lowest in "Agaiti-85" (9.11\%) followed by "Sultan" (12.23\%). Our study revealed that maize genotypes also had significant role on embryo rescue performance. Average embryo rescue best percentage

Table 4. Response of wheat $\times$ maize crosses on haploid seed production, embryo rescued, haploid embryo rescued from haploid seeds and embryo formed in florets.

\begin{tabular}{cccccccc}
\hline Crosses & $\begin{array}{c}\text { No. } \\
\text { Spikes }\end{array}$ & $\begin{array}{c}\text { No. } \\
\text { Florets }\end{array}$ & $\begin{array}{c}\text { No. Haploid } \\
\text { Seeds }\end{array}$ & $\begin{array}{c}\text { Haploid Seeds } \\
\text { Produced (\%) }\end{array}$ & $\begin{array}{c}\text { No. Embryos } \\
\text { Rescued }\end{array}$ & $\begin{array}{c}\text { Haploid } \\
\text { Embryo } \\
\text { Rescued (\%) }\end{array}$ & $\begin{array}{c}\text { Embryo } \\
\text { Formed in } \\
\text { Florets (\%) }\end{array}$ \\
\hline $\begin{array}{c}\text { Wheat }\left(F_{2}\right) \\
\text { X Sadaf }\end{array}$ & 60 & 780 & 223 & 28.58 & 45 & 20.17 & 5.35 \\
\hline $\begin{array}{c}\text { Wheat }\left(F_{2}\right) \\
\text { X Malka- } \\
2016\end{array}$ & 60 & 840 & 222 & 26.42 & 60 & 27.02 & 7.69 \\
\hline $\begin{array}{c}\text { Wheat }\left(F_{2}\right) \\
\text { X Pearl }\end{array}$ & 60 & 900 & 255 & 28.33 & 42 & 16.47 & 4.66 \\
\hline $\begin{array}{c}\text { Wheat }\left(F_{2}\right) \\
\quad \text { M MRI } \\
\text { yellow }\end{array}$ & 60 & 840 & 151 & 17.97 & 39 & 25.82 & 4.64 \\
\hline \begin{tabular}{c} 
Total \\
\hline
\end{tabular} & 240 & 3360 & 861 & 25.34 & 186 & 22.24 & 5.58 \\
\hline
\end{tabular}

Khan et al., ${ }^{5}$ studied haploid seed production using different maize genotypes and observed that average performance of haploid seed production in "Neelum" $(56.41 \%)$ as compared to other varieties i.e. Agaiti-2002 (48.69), Sultan (46.98), Agaiti-85 (46.41\%) and Sadaf (45.17\%). Xynias et al., ${ }^{2}$ studied maximum haploid seed $11.3 \%$ in cross Penios $\times$ Acheloos followed by $10.6 \%$ in Penios $\times \mathrm{KVZ} /$ Cgn while minimum in Vergina $\times$ Acheloos $(5.6 \%)$ after $12-14$ days of pollination. In the current study, $28.58 \%$ haploid seeds were developed after 12 days so this study confirmed that haploid seed production is the best in 12 days after pollination.

Maximum embryos rescued 27.02\% in "Malka-2016" followed by $25.82 \%$ in "MMRI yellow", $20.17 \%$ in "Sadaf" and lowest $16.47 \%$ in "Pearl" (Table 4). Niroula et al., ${ }^{10}$ analyzed different maize genotypes and the results showed that "Arun-2" formed 24 embryos out of 111 pollinated floret followed by "Khumal Yellow" which resulted in 22 embryos from 116 whereas "Rampur Composite" resulted in a minimum number of 5 embryos from 91 pollinated florets. In our studies the highest number of embryos were rescued when maize genotype Malka-2016 was used as pollinator.

The rescued embryos percentage ranges $4.64 \%$ to $7.69 \%$ in "MMRI yellow" and "Malka-2016", respectively. Khan et al., ${ }^{5}$ observed the highest average percentage of haploid was found in "Malka-2016" (27.02\%) followed by "MMRI yellow" (25.82\%) and lowest result observed in "Pearl" (16.47) Table 4. Embryo rescue percentage in our study is $(27.02 \%)$ found better comparatively $(19.13 \%)$ in Sadaf used by Khan et al., ${ }^{5}$. Male pollen source of Malka-2016 enabled us to produce higher number of haploid embryos rescued. Xynias et al., ${ }^{2}$ reported maximum haploid embryos percentage after 12 days of pollination (10.9\%) while $9.8 \%$ and $7.6 \%$ after 14 and 16 days of pollination, respectively. This study confirmed our finding regarding maximum embryos formation after 12 days of pollination.

Khan and Ahmad'11 emasculated wheat spikes and pollinated after 24, 48 and 72 hours. Embryo rescue ranged $0.0-9.52 \%$ after 72 hours, 0.0 to $7.48 \%$ after 48 hours and 2.22 to $9.09 \%$ after 24 hours at various temperature. In our study, embryos rescued range 4.64 to $7.69 \%$ after 72 hours of pollination at $22 \pm 2^{\circ} \mathrm{C}$ in the growth room. It was concluded the time of emasculation had vital role in embryos rescue percentage when pollinated after 72 hours. These finding conceded the previous work.

\section{CONCLUSION}

This study concluded specific maize genotypes are suitable for haploid seed production. Maize genotypes Sadaf and Malka-2016 are specific to produce haploid 
seed and embryo rescue, respectively so these genotypes are recommended as the best pollinators in wheat $\times$ maize crossing for obtaining maximum haploid seed formation and embryo rescue.

\section{REFERENCES}

1. Hussain B, Khan MA, Qurban A, Shadab S. Double Haploid Production is the Best Method for Genetic Improvement and Genetic Studies of Wheat. IJAVMS. 2012;6(4):216-28.

2. Xynias I, Koufalis A, Vavdinoudi EG, Roupakias D. Factors Affecting Doubled Haploid Plant Production Via Maize Technique in Bread Wheat. Acta Biologica Cracoviensia, Botanica. 2014;56(2):67-73.

3. Daniel G, Baumann A, Schmucker S. Production of wheat doubled haploids (Triticum aestivum L.) by wheat $x$ maize crosses using colchicine enriched medium for embryo regeneration. Cereal Research Communications. 2005; 33:461-68.

4. Campbell AW, Griffin WB, Burritt DJ, Conner AJ. Production of wheat doubled haploids via wide crosses in New Zealand wheat. NEW Zeal J Crop Hort. 2000;28(3):185-94.

5. Khan MA, Kashif M, Ahmad J, Khan AS, Khaliq I, Bilquees F, Shaukat S. SADAF- a potential donor for enhancing frequency of doubled haploids in wheat $x$ maize crossing system. Pak $J$ Agri Sci. 2014;51(2):363-7.
6. Kazi AM, Gul A, Ahmed J, Mirza JI. A simplified and effective protocol for production of bread wheat haploids $(n=3 x=21, A B D)$ with some application areas in wheat improvement. Pak $\mathrm{J}$ Bot. 2006;38(2):393-406.

7. Campbell AW, Griffin WB, Conner AJ, Rowarth JS, Burritt DJ. The effects of temperature and light intensity on embryo numbers in wheat doubled haploid production through wheatx maize crosses. Ann Bot. 1998;82(1):29-33.

8. Murashige T, Skoog F. A revised medium for rapid growth and bioassy with tobacco tissue culture. Physiol Plant. 1962; 15:473-97.

9. Khokhar MI, Iqbal MZ, Rehman S, Akhtar S, Javed K. Steps and factors in double haploid wheat plant production through wheat $\times$ maize cross - a review. J Agric Res. 2017;55(2):267-78.

10. Niroula RK, Bimb HP, Thapa DB, Sah BP, Nayak S. Production of haploid wheat plants from wheat (Triticum aestivum L.) x maize (Zea mays L.) cross system. Himalayan Journal of Sciences. 2007;4(6):65-9.

11. Khan MA, Ahmad J. In vitro wheat haploid embryo production by wheat $x$ maize cross system under different environmental conditions. Pak J Agri Sci. 2011;48(1):49-53. 